\title{
PEMANFAATAN BERBAGAI TANAMAN REFUGIA SEBAGAI PENGENDALI HAMA ALAMI PADA TANAMAN CABAI (Capsicum annum L.)
}

\author{
Dwiwiyati Nurul Septariani ${ }^{1 *}$, Aktavia Herawati ${ }^{2}$, Mujiyo $^{2}$ \\ ${ }^{1}$ Program Studi Agroteknologi; ${ }^{2}$ Program Studi Ilmu Tanah \\ Fakultas Pertanian, Universitas Sebelas Maret \\ *Korespondensi: dwiwiyatinurul@staff.uns.ac.id
}

\begin{abstract}
ABSTRAK
Tanaman cabai merupakan komoditas dengan nilai ekonomis tinggi di Desa Srigading, Kecamatan Sanden, Kabupaten Bantul. Produktivitas cabai di lahan sub-optimal pasir pantai tidak kalah tinggi dibandingkan dengan lahan sawah. Namun penurunan produktivitas cabai yang disebabkan serangan organisme pengganggu tanaman mengakibatkan kerugian bagi petani, sehingga perlu dilakukan pengendalian OPT. Edukasi tentang pemanfaatan tanaman refugia sebagai pengendali hama alami belum pernah dilakukan. Metode yang dilakukan dalam kegiatan ini adalah paparan (edu-agriculture) tentang pemanfaatan tanaman refugia, pembuatan demonstrasi plot tanaman cabai dengan berbagai jenis tanaman refugia, serta inisiasi wisata swafoto bunga. Hasil kegiatan yang diperoleh berupa peningkatan pengetahuan mengenai teknik pengendalian hama dan penyakit secara alami sehingga mengurangi ketergantungan terhadap pestisida sintetik dengan memanfaatkan tanaman refugia yang terdapat di lingkungan sekitar. Kegiatan terbukti mengatasi permasalahan para petani dan memanfaatkan sumber daya alam secara maksimal yang sangat penting bagi peningkatan produktivitas pertanian.
\end{abstract}

Kata kunci: trap-croping, musuh alami, swafoto

\section{PENDAHULUAN}

Desa Srigading, Kecamatan Sanden. Kabupaten Bantul merupakan sentra komoditas cabai (Capsicum annum L). Berbagai kultivar cabai dibudidayakan oleh petani setempat. Selain di lahan basah/sawah, petani membudidayakan cabai di lahan suboptimal pasir pantai yang membentang di sepanjang pantai selatan dari timur sampai ke barat sepanjang $30 \mathrm{~km}$ seluas $6.446 \mathrm{Ha}$. Menurut Badan Pusat Statistik (2016), produksi cabai merah di Desa Srigading mengalami penurunan. Pada tahun 2012 produksi cabai sebesar $34,33 \mathrm{Kw} / \mathrm{Ha}$, tahun 2013 turun menjadi 30,38 Kw/Ha dan puncak penurunan terjadi pada tahun 2014 yaitu sebesar 16,77 Kw/Ha. Penurunan produksi ini disebabkan oleh serangan organisme pengganggu tanaman. Untuk meningkatkan produksi, petani menggunakan pestisida kimia secara besar-besaran. Ini terbukti dengan produktivitas cabai pada tahun 2015 meningkat menjadi 40,77 Kw/Ha.

Penanganan organisme pengganggu tanaman (OPT) yang kurang tepat mengakibatkan kerugian yang cukup besar baik berupa kehilangan hasil (kuantitas) dan penurunan mutu (kualitas) tanaman. Penggunaan pestisida kimia yang tidak tepat dapat memberikan dampak seperti resistensi hama, resurjensi hama atau peningkatan populasi keturunan-keturunan hama, matinya hewan non target termasuk musuh alami, timbulnya ledakan hama sekunder, residu pestisida pada tanaman dan lingkungan. Selain itu residu pestisida yang terdapat pada produk pertanian sangat berbahaya jika dikonsumsi dalam jangka waktu yang panjang. Permasalahan inilah yang dialami oleh mitra yaitu anggota Majelis Taklim Nailul Hidayah yang semuanya berprofesi 
sebagai petani. Sehingga dibutuhkan solusi/tindakan yang dapat mengurangi kerugian petani akibat serangan OPT pada tanaman cabai.

Alternatif yang dapat diberikan sebagai upaya strategi budidaya berdasarkan keragaman hayati maka perlu dilakukan pengendalian hama yang ramah pada lingkungan khususnya musuh alami. Pengendalian OPT berdasar keragaman hayati akan mengefisienkan penggunaan lahan untuk peningkatan hasil produksi pertanian dan meningkatkan kehadiran musuh alami serta kompetitor bagi hama untuk mengurangi kerusakan tanaman. Upaya ini dapat diwujudkan dengan penanaman refugia yang berfungsi sebagai sumber pakan, inang/mangsa alternatif untuk musuh alami. Refugia adalah pertanaman beberapa jenis tumbuhan yang dapat menyediakan tempat perlindungan, sumber pakan atau sumberdaya yang lain bagi musuh alami seperti predator dan parasitoid. Refugia adalah tumbuhan (baik tanaman maupun gulma) yang tumbuh di sekitar tanaman yang dibudidayakan, yang berpotensi sebagai mikrohabitat bagi musuh alami (baik predator maupun parasit) tentunya agar pelestarian musuh alami tercipta dengan baik.

Tanaman refugia yang banyak tumbuh di lokasi mitra yaitu bunga kertas (Zinnia sp), bunga kenikir (Cosmos caudatus), bunga matahari (Helianthus annuus L. ), bunga jengger ayam (Celosia cristata), dan bunga jengger ayam kipas (Celosia plumosa). Tanaman refugia ini mempunyai sifat mudah tumbuh, cepat berkembang dan mempunyai warna serta aroma yang khas sehingga disukai oleh serangga. Berbagai jenis refugia tumbuh subur dan melimpah di lokasi mitra. Namun selama ini petani belum mengetahui manfaat dari tanaman tersebut.

Upaya pengendalian hama juga dapat dilakukan dengan memasang perangkap hama. Penggunaan perangkap serangga menggunakan atraktan atau zat penarik merupakan salah satu teknik pencuplikan serangga yang telah banyak digunakan baik dalam monitoring populasi maupun pengendalian hama (Prawiandiputra et al. 2015). Perangkap menggunakan zat penarik baik stimulus kimia maupun fisik seperti cahaya, warna, atau senyawa kimia sehingga menyebabkan serangga dapat tertarik ke dalam perangkap (Yi et al. 2012). Atraktan atau zat penarik merupakan zat kimia yang dapat menyebabkan serangga bergerak mendekati sumber zat tersebut. Kairomon atau feromon merupakan dua tipe atraktan yang dapat menarik serangga. Kairomon merupakan zat penarik yang dikeluarkan oleh suatu spesies untuk menarik spesies yang berbeda, sedangkan feromon mampu menarik spesies yang sama (Schoonhoven et al. 2005).

Berdasarkan hal ini maka pemilihan Majelis Taklim Nailul Hidayah (MTNH) sebagai mitra dalam kegiatan pengabdian ini sangatlah tepat. Majelis Taklim Nailul Hidayah (MTNH) adalah mitra yang disasar dalam kegiatan yang berlokasi di Dusun Sogesanden RT 76 Desa Srigading, Kecamatan Sanden, Kabupaten Bantul, Daerah Istimewa Yogyakarta. MTNH beranggotakan para ibu yang mayoritas berprofesi sebagai petani dengan komoditas utama cabai. MTNH membutuhkan kegiatan yang dapat mengatasi permasalahan mereka tentang penanganan organisme pengganggu tanaman (OPT) secara alami dan peningkatan pengetahuan bertani terutama tentang pemanfaatan tanaman refugia sebagai agensia pengendali hayati serta penataan/lanscape refugia sebagai wisata swafoto. Penataan/lay-out tanaman bunga sebagai refugia harus berdasarkan fungsi dan manfaat bunga. Sehingga dibutuhkan transfer pengetahuan dan pendampingan agar pemanfaatan tanaman refugia sesuai dengan sasaran dan tujuan yang hendak dicapai oleh mitra. 
Berdasarkan analisis situasi tersebut, maka dapat disimpulkan permasalahan utama yang dihadapi mitra, yaitu: (1) Penurunan produksi cabai akibat serangan Bemisia tabacci karena minimnya pengetahuan tentang tanaman refugia sebagai OPT, (2) Perlu contoh kongkrit tentang manfaat tanaman refugia yang berfungsi sebagai habitat musuh alami dan agensia pengendali hama, (3) Mitra belum mengetahui cara perbanyakan dan penerapan/lansekap taman tanaman refugia, dan (4) Inisiasi wisata swafoto bunga dengan tanaman refugia. Keuntungan penggunaan tanaman refugia berupa bunga adalah murah, mudah ditanam dan mudah diperbanyak. Selain itu tanaman bunga tersebut terdapat banyak di lokasi mitra sehingga secara ekonomi tidak membebani mitra. Tanaman bunga tersebut juga memiliki warna-warna yang menarik dan mencolok sehingga dapat meningkatkan nilai jual dan menginisiasi wisata swafoto. Wisatawan akan tertarik dan berkunjung untuk melakukan swafoto bunga. Sehingga penataan bunga yang disesuaikan dengan fungsi serta arsitektur taman perlu dilakukan. Jika penataan bunga ini menarik dan sesuai dengan kaidah keilmuan maka akan semakin banyak wisatawan yang berkunjung. Dengan demikian mitra akan memperoleh tambahan penghasilan melalui biaya retribusi lokasi wisata.

Tujuan khusus dari kegiatan ini adalah mengurangi ketergantungan petani terhadap pestisida sintetik dengan mengintroduksi tanaman refugia yang ada di lingkungan sekitar sebagai pengendali hama alami. Pemanfaatan sumber daya alam tersebut secara maksimal sangat berarti bagi peningkatan produktivitas dan pendapatan petani serta pembangunan dalam sektor pertanian.

\section{METODE}

Tahapan/metode dalam pelaksanaan kegiatan disusun untuk mempermudah dalam mencapai target/tujuan. Tahapan-tahapan dan metode yang akan dilakukan meliputi survei lokasi, edukasi/paparan dan sosialisasi tentang manfaat tanaman refugia, demonstrasi plot, inisiasi lokasi wisata swafoto bunga.

\section{Edukasi/paparan dan sosialisasi tentang manfaat tanaman refugia sebagai pengendali OPT pada tanaman cabai.}

Dalam kegiatan ini akan dijelaskan mengenai tanaman refugia, macam tanaman refugia, mengenal tanaman refugia yang ada di lokasi mitra, dan manfaat tanaman refugia sebagai pengendali hama alami pada tanaman cabai serta berbagai organisme pengganggu tanaman dari golongan hama dan penyakit tanaman cabai. Kegiatan ini akan mengundang perangkat desa terkait dengan peserta ibu-ibu petani yang aktif dalam organisasi mitra.

\section{Demonstrasi plot}

Demonstrasi plot adalah plot percobaan yang merupakan metode penyuluhan pertanian kepada petani, dengan cara membuat lahan percontohan, agar petani bisa melihat dan membuktikan terhadap objek yang didemontrasikan. Demonstrasi plot berupa budidaya cabai dengan menerapkan berbagai tanaman refugia yang ada di lokasi mitra sebagai trap croping untuk mengendalikan OPT. Demonstrasi plot ini akan tersusun dari beberapa blok dengan luas $1 \times 7 \mathrm{~m}$, dan setiap blok akan dikelilingi oleh 1 jenis tanaman refugia.

\section{Pemasangan perangkap hama}

Pencuplikan serangga hama dilakukan dengan teknik perangkap dengan menggunakan atraktan metil eugenol. Metil eugenol diteteskan ke kapas lalu dimasukkan ke dalam perangkap yang telah dibuat dari bekas botol kemasan air mineral. Botol perangkap diletakkan pada pertanaman cabai yang telah diberi ajir menggunakan kawat dengan ketinggian kira-kira $60 \mathrm{~cm}$ di 
pertanaman cabai merah yang tujuannya agar aroma metil eugenol dapat menarik lalat jantan. Pemasangan perangkap dilakukan pada waktu serangga sedang aktif terbang yaitu pada pagi atau siang hari.

\section{Pembangunan/Inisiasi lokasi wisata swafoto bunga}

Kegiatan ini bertujuan untuk menambah keterampilan mitra dalam memanfaatkan peluang tanaman refugia sebagai lokasi swafoto sekaligus bertanam cabai. Tujuan yang hendak dicapai dalam kegiatan ini yaitu peningkatan perekonomian mitra.

Peran serta dan keaktifan mitra menjadi kunci penting dalam kesuksesan pelaksanaan program ini. Mitra dituntut untuk aktif dan bersedia menyiapkan lokasi/lahan yang akan digunakan sebagai lokasi demonstrasi plot dan inisiasi wisata swafoto tanaman refugia. Evaluasi keberlanjutan program akan dilakukan dengan memonitoring seluruh kegiatan dengan melakukan kunjungan secara berkala ke lokasi mitra. Selain itu evaluasi keberlanjutan program dapat dilakukan dengan melaksanakan pengabdian mandiri di lokasi mitra, sehingga komunikasi antara mitra dan pengusul selalu terjaga.

\section{HASIL DAN PEMBAHASAN}

\section{Edukasi dan Sosialisasi Manfaat Tanaman Refugia}

Kegiatan Penyuluhan "Pemanfaatan Berbagai Tanaman Refugia sebagai Pengendali Hama Alami pada Tanaman Cabai (Capsicum annuum L.)" telah dilaksanakan di Balai Pertemuan Yayasan Ibnu Sina, Desa Srigading, Kecamatan Sanden, Kabupaten Bantul. Peserta pelatihan diberikan materi secara luas mengenai budidaya tanaman cabai yang tepat serta perawatannya. Pembahasan budidaya tanaman cabai meliputi cara pengendalian hama secara alami dengan pemanfaatan tanaman untuk mengendalikan berbagai hama pada tanaman cabai. Metode pengendalian hama secara alami terutama difokuskan dengan pemanfaatan tanaman refugia sebagai upaya konservasi habitat musuh alami yang dapat menekan keberadaan hama tanaman cabai.

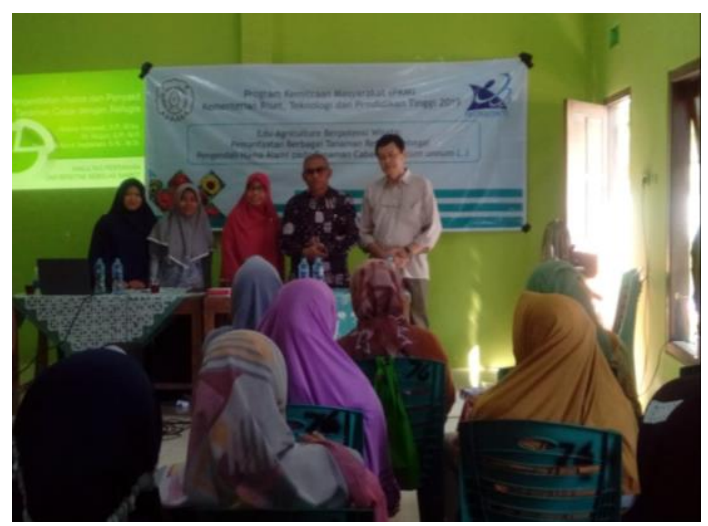

Gambar 1. Penyuluhan dihadiri Kepala Desa Srigading

Penyampaian materi dimulai dari pemahaman mengenai beberapa penyebab penurunan adanya penurunan produksi tanaman cabai yang menyebabkan pendapatan petani menurun. Penurunan produksi ini salah satunya disebabkan oleh adanya gangguan hama dan penyakit pada tanaman cabai. Berbagai upaya dapat dilakukan untuk mengendalikan hama dan penyakit pada tanaman cabai, antara lain perlakuan kultur teknis, penggunaan varietas tanaman tahan, dan pengendalian hayati. Pengendalian hama yang dilakukan oleh para petani di lokasi kegiatan pengabdian selama ini masih menggunakan bahan kimia. Penggunaan pestisida kimia secara berlebihan dan terus menerus akan menimbulkan dampak buruk bagi kondisi tanah maupun tanaman. Kegiatan ini penyuluhan ini mengupayakan pemahaman kepada para petani untuk melakukan pengendalian secara alami. 

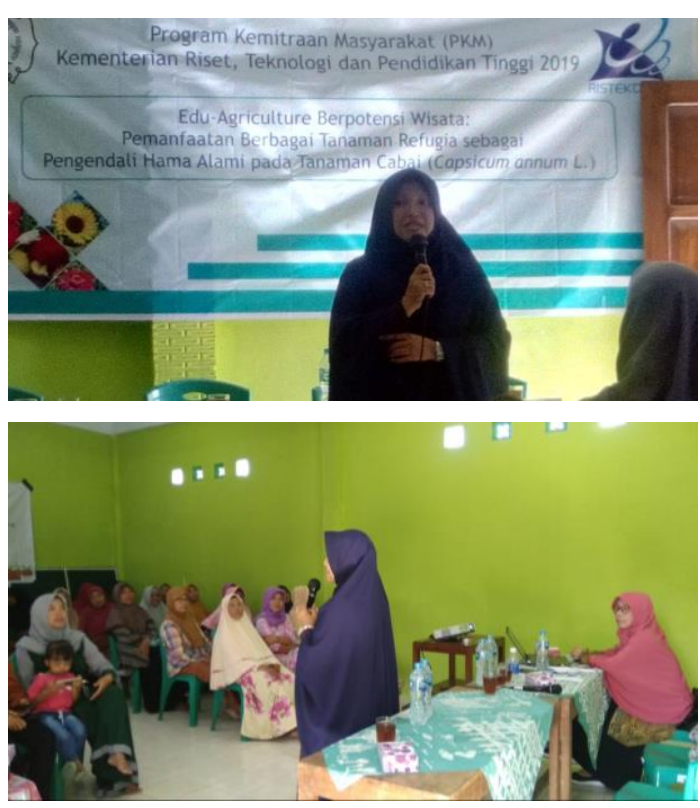

Gambar 2. Penyampaian Materi Pemanfaatan Refugia

Penggunaan insektisida kimia dalam dosis tinggi sangat mempengaruhi struktur komunitas serangga dan berpengaruh langsung terhadap musuh alami. Keberadaan musuh alami merupakan salah satu faktor penting dalam menjaga keseimbangan ekosistem. Tinggi rendahnya populasi serangga secara umum menunjukkan erat hubungannya dengan fase tumbuh tanaman yang menjadi ketersediaan sumber makanan bagi pertumbuhan dan perkembangan serangga (Latoantja et al. 2013). Keragaman serangga yang tinggi mengindikasikan tingkat elastisitas yang tinggi dalam menghadapi guncangan dalam ekosistem, dan sebaliknya ekosistem dengan keragaman rendah menunjukkan tekanan sehingga mempengaruhi kualitas ekosistem (Apriliyanto dan Sarno 2018).

Pengelolaan hama terpadu menggunakan metode pengendalian alami merupakan praktek pertanian yang mendukung perlindungan tanaman. Penggunaan tanaman perangkap/refugia merupakan salah satu metode yang dapat dilakukan. Tanaman berbunga yang ditanam secara berselang dapat meningkatkan populasi musuh alami dan dapat menekan populasi hama kutu (Skirvin et al. 2011).

Keberadaan tanaman refugia juga mendukung kehidupan serangga musuh alami. Setidaknya terdapat enam jenis tumbuhan yang mampu meningkatkan ketegaran serangga predator (Laubertie et al. 2012). Tanaman refugia yang ditanam di sekitar pertanaman budidaya cabai di daerah lokasi mitra diharapkan dapat memikat serangga hama dari tanaman utama ke tanaman berbunga. Tumbuhan berbunga menarik kedatangan serangga menggunakan karakter morfologi dan fisiologi dari bunga, yaitu ukuran, bentuk, warna, keharuman, periode berbunga, serta kandungan nektar dan polen. Kebanyakan dari serangga lebih menyukai bunga yang berukuran lebih kecil, cenderung terbuka, dengan waktu berbunga yang cukup lama yang biasanya terdapat bunga dari family Compositae atau Asteraceae (Kurniawati dan Martono 2015).

Selain karakter morfologi dan fisiologi dari bunga, faktor lain yang mempengaruhi kedatangan serangga pada suatu bunga adalah faktor lingkungan fisik yaitu cahaya, suku, kelembaban, serta kecepatan dan arah angin. Respons serangga terhadap lingkungan fisik ini berbeda sehingga waktu aktifnya pun berbeda, yaitu pagi, siang, sore, atau malam hari (Kurniawati dan Martono 2015).

Pengelolaan sistem bertanam perlu dilakukan sebagai upaya melakukan konservasi serangga musuh alami. Pengelolaan habitat musuh alami merupakan upaya memanipulasi habitat lokal agar sesuai bagi musuh alami sehingga daya tekan terhadap populasi hama meningkat. Sistem tanam ini relatif mudah dan murah untuk dilakukan, secara ekonomi lebih menguntungkan, dan tidak mencemari lingkungan karena menggunakan masukan rendah, misalnya bahan organik sebagai pupuk, serta musuh alami, dan tanaman 
perangkap hama sebagai pengendali hama (Altieri dan Nichols 2004).

Sistem tanam inter cropping, strip cropping, dan alley cropping adalah menanam tumbuhan berbunga di antara tanaman utama (sistem lorong atau baris) yang berfungsi sebagai tanaman perangkap, atau sebagai sumber pakan musuh alami. Insectary plant dan tumbuhan penutup tanah (cover crop) merupakan tumbuhan berbunga yang ditanam bersamaan dengan tanaman budidaya sebagai sumber pakan dan inang alternatif (Altieri dan Nichols 2004).

Pemilihan tumbuhan berbunga pada sistem polikultur harus memperhatikan fungsi dan peran dari tumbuhan tersebut di lingkungan, misalnya potensi untuk meningkatkan kedatangan musuh alami, meningkatkan kesuburan tanah, atau menekan populasi gulma). Telah dibuktikan pengujian keamanan biologis terhadap bunga matahari Helianthus annuus (Zhon et al. 2011). Selain itu penanaman tumbuhan berbunga harus memperhitungkan struktur dan komposisinya yang disesuaikan dengan kondisi lahan setempat (Magagula 2011). Periode berbunga dari masing-masing tumbuhan juga diperhatikan sehingga mampu menjaga populasi musuh alami tetap tinggi di sepanjang musim tanam (Heshula 2011).

Tanaman refugia yang dimanfaatkan di daerah lokasi mitra disesuaikan dengan ketersediaan jenis tanaman yang ada, antara lain bunga kertas pink tumpuk (Zinnia elegans), bunga kertas pink (Zinnia peruviana), bunga kertas kuning (Zinnia peruviana), bunga kertas orange (Zinnia peruviana), bunga kenikir kuning (Cosmos caudatus), bunga kenikir orange (Cosmos caudatus), bunga matahari (Helianthus annuus), bunga jengger ayam (Celosia cristata), bunga jengger ayam kipas kuning (Celosia plumosa), dan bunga jengger ayam kipas merah (Celosia plumosa).

\section{Demonstrasi plot}

Kegiatan pengabdian dengan tema edu-agriculture telah menghasilkan pemahaman lebih mendalam bagi para petani tanaman cabai di lokasi mitra mengenai pemanfaatan tanaman refugia sebagai pengendali hama dan penyakit sehingga produktivitas tanaman cabai dapat meningkat dan pendapatan para petani pun lebih meningkat. Untuk itu dilakukan demonstrasi plot tanaman cabai sebagai contoh konkrit pemanfaatan tanaman berbunga dengan membuat lahan percontohan agar petani dapat melihat dan membuktikan objek yang didemonstrasikan. Demonstrasi plot tersusun dari beberapa blok yang disusun sesuai layout untuk memudahkan memberi contoh penanaman refugia.
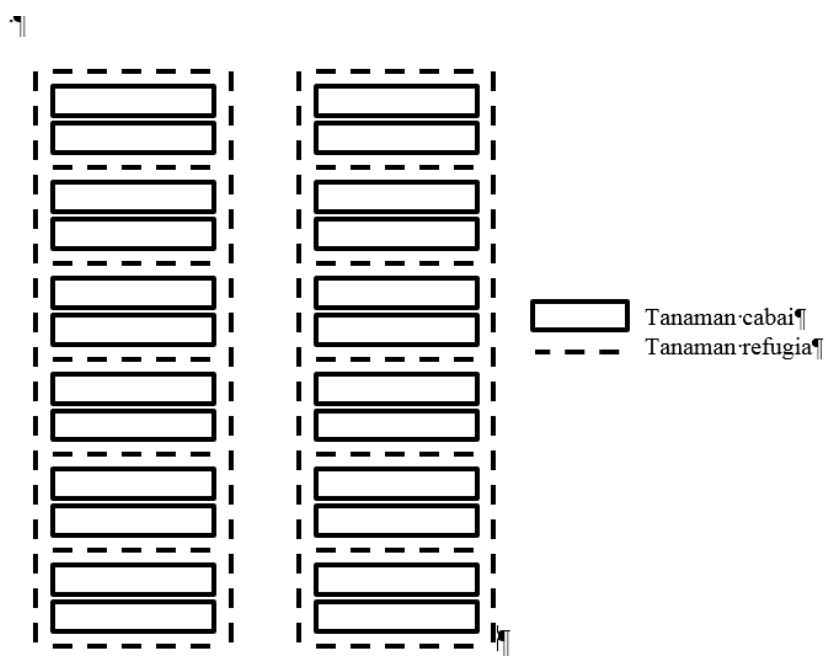

Gambar 3. Layout penanaman cabai dan refugia

Demonstrasi plot merupakan salah satu metode terbaik untuk memperbaiki hasil dan dimanfaatkan oleh para penyuluh untuk memperoleh perubahan perilaku yang diinginkan masyarakat. Adanya demplot akan tercipta komunikasi dan interaksi antara penyuluh dan petani. Selain itu terdapat perubahan pengetahuan, opini, dan keterampilan (Radhakrishna 2010).

Tempat dan waktu penanaman refugia perlu diperhatikan agar tanaman dapat 
tumbuh dengan baik dan mendukung tujuan kegiatan yaitu mengendalikan hama dan membuat adanya lokasi wisata. Penanaman tanaman refugia agar tepat guna dilakukan di sepanjang pinggir pertanaman cabai. Tanaman refugia yang ditanam melalui biji maka sebaiknya tanah digemburkan dulu dan diberi pupuk. Penanaman dilakukan secara serempak saat pengelolaan lahan sehingga saat pertanaman cabai mulai tumbuh bersamaan dengan tanaman refugia mulai berbunga dan mencegah serangan hama sejak awal.

\section{Pemasangan perangkap hama}

Upaya pengendalian hama juga dilakukan dengan kegiatan pemasangan perangkap dengan bahan dasar metil eugenol. Penggunaan atraktan dengan menggunakan bahan metil eugenol merupakan cara pengendalian yang ramah lingkungan dan telah terbukti efektif. Pembuatan perangkap sangat sederhana dengan bahan yang mudah diperoleh sehingga menjadi metode pengendalian yang praktis dan kompatibel.

Metil eugenol merupakan senyawa pemikat serangga terutama untuk lalat buah jantan. Sifat kimiawi dari metil eugenol yang relatif mirip dengan pheromone seks yang dihasilkan oleh lalat buah betina untuk menarik lalat buah jantan dalam rangka kopulasi. Ketika zat tersebut dilepaskan oleh lalat buah betina maka lalat buah jantan akan berusaha mencari lalat buah betina yang melepaskan aroma tersebut. Dalam hal ini metil eugenol merupakan zat kimia yang bersifat volatile ataupun dapat menguap dan melepaskan aroma wangi. Radius aroma dari atraktan seks itu dapat mencapai 20-100 m dan jika dibantu angin, jangkauannya dapat mencapai $3 \mathrm{~km}$ (Manurung dan Ginting 2010).

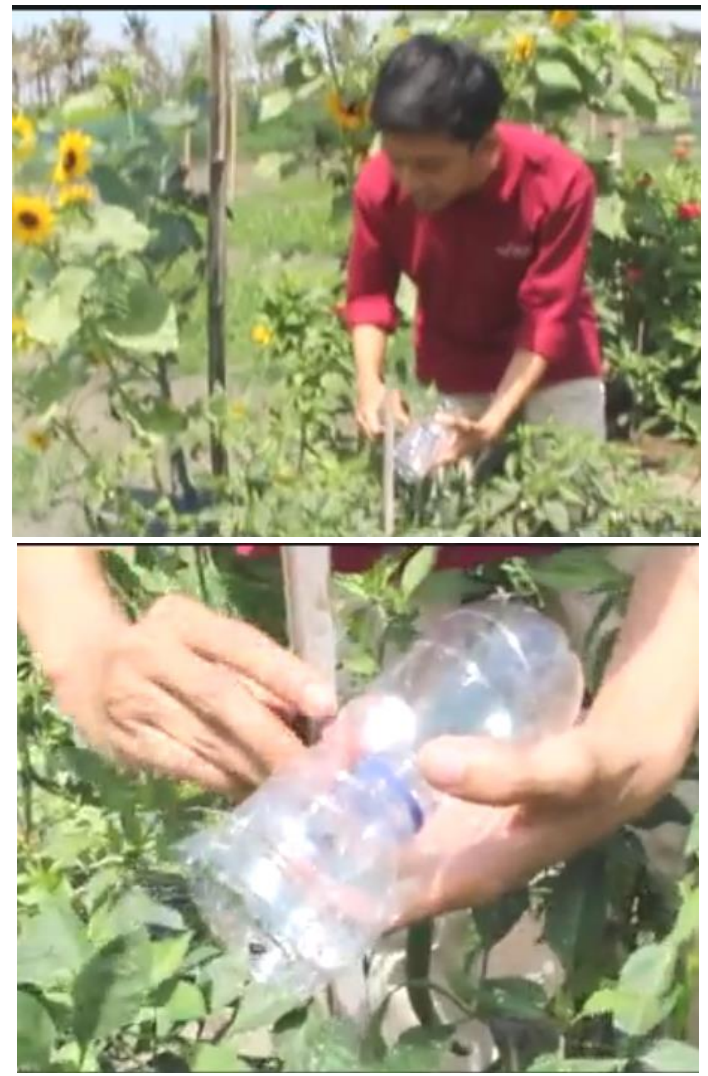

Gambar 4. Pemasangan perangkap hama dengan metil eugenol

Penggunaan metil eugenol merupakan cara pengendalian yang ramah lingkungan dan telah terbukti efektif. Atraktan dapat digunakan untuk mengendalikan hama dengan mendeteksi atau memonitor populasi hama, menarik hama untuk kemudian dimusnahkan dalam perangkap, dan mengacaukan hama dalam perkawinan, berkumpul dan cara makan. Metil eugenol tidak meninggalkan residu pada tanaman dan mudah dipalikasikan pada lahan yang luas. Daya tangkap atraktan bervariasi tergantung pada lokasi, cuaca, komoditas dan keadaan buah di lahan pertanaman.

\section{Inisiasi lokasi wisata swafoto}

Kegiatan dilanjutkan dengan inisiasi lokasi wisata swafoto bunga dengan tanaman refugia dipadu dengan tanaman cabai. Era sosial media sesuai kondisi masyarakat saat ini membuat semua orang memiliki hobi swafoto. Oleh karena itu, inisiasi ini 
dilakukan untuk menarik wisatawan yang antusias terhadap fotografi, swafoto, dan media sosial. Selain wisata swafoto, Desa Srigading menjadi lokasi wisata edukatif untuk mempelajari pemanfaatan tanaman refugia sebagai pengendali hama pada tanaman cabai.

Pada akhirnya kegiatan ini akan meningkatkan nilai daerah lokasi mitra agar lebih dikenal masyarakat luas di Indonesia. Melalaui kegiatan ini masyarakat terutama para petani secara mandiri akan terpacu memelihara pertanaman cabai dan tanaman berbunga serta daerah lokasi secara luas. Dengan demikian masyarakat di daerah lokasi pengabdian akan terus berkembang.

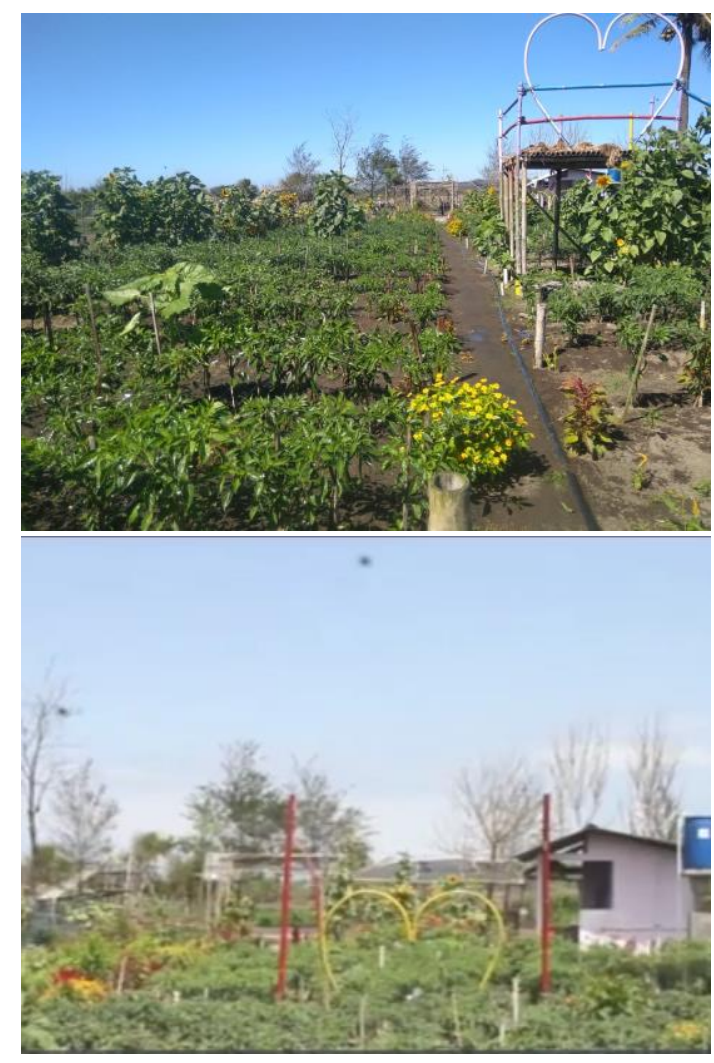

Gambar 5. Spot swafoto diantara pertanaman cabai dan refugia

Pemantauan terus dilakukan untuk mengetahui perkembangan pengetahuan serta keterampilan yang telah diperoleh para petani. Selain itu juga perkembangan kesehatan tanah dan tanaman cabai setelah dilakukan penanaman refugia sebagai upaya menekan populasi hama dan penyakit pada pertanaman cabai yang dikelola oleh para petani. Selain itu para petani diharapkan dapat merasakan dan mengutarakan kemajuan masyarakat di lokasi mitra dalam perekonomian maupun kesejahteraannya.

\section{KESIMPULAN}

Berdasarkan uraian dalam laporan kemajuan ini dapat disimpulkan bahwa para petani sebagai peserta penyuluhan menunjukkan keaktifan yang ditunjukkan dengan sikap interaktif dan minat yang tinggi untuk berpartisipasi dalam membangun daerahnya. Peserta penyuluhan pemanfaatan tanaman refugia memperoleh transfer pengetahuan mengenai teknik pengendalian hama dan penyakit secara alami sehingga mengurangi ketergantungan terhadap pestisida sintetik dengan memanfaatkan tanaman refugia yang terdapat di lingkungan sekitar. Kegiatan pengabdian di Desa Srigading Kecamatan Sanden Kabupaten Bantul mengatasi permasalahan para petani dan memanfaatkan sumber daya alam secara maksimal yang sangat penting bagi peningkatan produktivitas dan pendapatan petani serta pembangunan dalam sektor pertanian.

\section{DAFTAR PUSTAKA}

Altieri MA, Nichols CI. 2004. Biodiversity and pest management in agroecosystem. $2^{\text {nd }}$ Edition. Haworth Press Inc., New York.

Apriliyanto E, Sarno. 2018. Pemantauan keanekaragaman hama dan musuh alami pada ekosistem tepid an tengah tanaman kacang tanah (Arachis hypogeal L.). majalah Ilmiah Biologi Biosfera: A Scientific Journal 35(2): 69-74

Badan Pusat Statistik. 2016. Kabupaten Bantul dalam Angka 2016. Bantul: BPS Kabupaten Bantul 
Heshula LUP, Hill MP. 2011. The effect of Lantana camara leaf quality on the performance of Falconia intermedia. Biocontrol 56: 925-933.

Kurniawati N, Martono E. 2015. Peran tumbuhan berbunga sebagai media konservasi arthropoda musuh alami. Jurnal Perlindungan Tanaman Indonesia 19(2): 5-59.

Latoantja AS, Hasriyanti, Anshary A. 2013. Inventarisasi arthropoda pada permukaan tanah di pertanaman cabai (Capsicum annum L.). J. Agrotekbis 1(5): 406-412

Laubertie EA, Wratten SD, Hemptinne JL. 2012. The contribution of potential beneficial insectary plant species to adult hoverfly fitness. Biological Control 61: 1-6.

Magagula CN. 2011. Distribution and abundance of Ophymia camarae (Diptera:Agromyzidae) in Lantana camara (Verbenaceae) in selected area of Swaziland. Biocontrol Science and Technology 21: 829-837.
Manurung, B. \& Ginting, E.L. 2010. Efektifitas Atrakan dalam Memerangkap Lalat Buah Bactrocera spp. dan Kajian Awal Fluktuasi Populasinya pada Pertanaman Jeruk di Kabupaten Karo. Jurnal Sains Indonesia 34(2):96-99.

Radhakrishna R. 2010. Viewing Bennett's Hierarchy from a different lens: Implications for extension program evaluation. J Extention 48(6) Article Number 6TOT1, Pp.5.

Skirvin DJ, Garde KL, Reynolds KW, Mead A. 2011. The effect of within - crop habitat manipulation on the conservation biologicalcontrol of aphids in field grown lettuce. Buletin of Entomological Research 101: 62-631.

Zhon Z, Guo JY, Zheng XW, Luo M,Chen HS,Han FW. 2011. Reevaluation in the biosecurity of Ophraella communa againstsunflower Helianthus annuus. Biocontrol Science and Technology 21: 1147-1160. 